\title{
Quantifying Loss Caused by Ray Blight Disease in Tasmanian Pyrethrum Fields
}

Sarah J. Pethybridge, Tasmanian Institute of Agricultural Research (TIAR), University of Tasmania, P.O. Box 3523, Burnie, Tasmania, 7320, Australia; Paul Esker, Department of Plant Pathology, Iowa State University, Ames 50011, USA; Phillip Dixon, Department of Statistics, Iowa State University, Ames 50011, USA; Frank Hay, TIAR, University of Tasmania, P.O. Box 3523, Burnie, Tasmania, 7320, Australia; Tim Groom, Botanical Resources Australia Pty. Ltd., 44-46 Industrial Drive, Ulverstone, Tasmania, 7315, Australia; Calum Wilson, TIAR, University of Tasmania, New Town Research Laboratories, 13 St. Johns Ave., New Town, Tasmania, 7008, Australia; and Forrest W. Nutter Jr., Department of Plant Pathology, Iowa State University, Ames 50011, USA

\begin{abstract}
Pethybridge, S. J., Esker, P., Dixon, P., Hay, F., Groom, T., Wilson, C., and Nutter, F. W., Jr. 2007. Quantifying loss caused by ray blight disease in Tasmanian pyrethrum fields. Plant Dis. 91:1116-1121.

The efficacy of newly implemented fungicide recommendations on reducing the intensity of ray blight disease caused by Phoma ligulicola to achieve site-specific attainable yield potentials in Tasmanian pyrethrum fields was quantified over two seasons in 46 and 51 fields during the 2003 and 2004 growing seasons, respectively. Disease intensity and yield in two plots $(10 \times 24 \mathrm{~m})$, one following the commercial fungicide protocol recommendations and the second receiving no fungicide, were assessed in each pyrethrum field. The commercial fungicide protocol consisted of one application of azoxystrobin at $150 \mathrm{~g}$ a.i./ha, followed by two applications of a tank mixture of difenoconazole at $125 \mathrm{~g}$ a.i./ha and chlorothalonil at 1,008 liters a.i./ha at 14- to 21-day intervals. This program resulted in significant decreases in defoliation severity and the incidence of stems and flowers with ray blight, and increases in the height of stems and number of flowers produced per stem in October and November. In plots receiving the commercial fungicide protocol, the dry weight of flowers was increased by 76 and $68 \%$ in 2003 and 2004, respectively. Moreover, pyrethrin yield increased by 81 and $78 \%$ when the commercial fungicide protocol was used compared with the nontreated plots. Tobit regression was used to examine the relationships and thresholds among disease intensity measures (defoliation severity, stem severity, and incidence of flowers with ray blight) assessed just prior to harvest. This regression utilized a leftcensored regression model to define subminimal thresholds, as none of the disease intensity measures could be less than 0 . Defoliation severity had a threshold of $35.3 \%$ before stem severity linearly increased and a threshold of $38.2 \%$ before the incidence of flowers with ray blight linearly increased. Finally, the threshold for stem severity was $13.7 \%$ before the incidence of flowers with ray blight linearly increased. These thresholds can be used to assist growers in making disease management decisions with the objective of minimizing loss of flowers by maintaining defoliation severity below the critical point at which the incidence of flowers with ray blight begins to linearly increase.
\end{abstract}

Additional keywords: disease loss, yield loss

Pyrethrum (Tanacetum cinerariaefolium L.) is a perennial plant belonging to the Compositae family (5). Pyrethrum is cultivated primarily to extract pyrethrins, which are key ingredients in numerous natural insecticidal products for use in organically produced crops. Australian pyrethrum is produced solely in the state of Tasmania. During the 2004-2005 growing season, approximately 2,000 ha of pyrethrum were harvested, accounting for approximately $25 \%$ of the world market with an estimated worth of approximately

Corresponding author: S. J. Pethybridge

E-mail: sarah_jp@utas.edu.au

Accepted for publication 30 March 2007.

doi:10.1094/PDIS-91-9-1116

(C) 2007 The American Phytopathological Society ing necrotic leaf spots that coalesce and encompass the entire leaf surface, followed by the initiation of necrotic stem lesions associated with leaf death (18). Stem lesions can result in girdling; however, the most damaging aspect of this disease in terms of yield loss occurs when the developing terminal buds become infected in early spring. While each symptom has been well described, little is known of the thresholds for these different disease symptoms, which can be quantitatively assessed on the same sampling units. For example, can loss of flowers from ray blight disease be minimized by reducing defoliation severity and/or the severity of necrotic lesions on stems? This information is important because in the absence of spring fungicides, $100 \%$ crop loss is possible (19).

Cost-effective disease management of ray blight in chrysanthemum has primarily relied upon the use of resistant and/or late flowering disease-free certified cultivars $(1,2,27)$. Prior to the development and use of resistant cultivars and the development of strict certification schemes in the 1960s, regular applications of protectant fungicides were found to be a cost-effective disease management tactic $(1,2,3,27)$. In pyrethrum, various fungicides have been reported to be efficacious in managing ray blight disease (21), and results from this research were used to develop an industrywide commercial fungicide protocol that has been widely adopted by the Australian pyrethrum industry since 2002 . This protocol consists of a single application of azoxystrobin at $150 \mathrm{~g}$ a.i./ha (as Amistar WG; Syngenta Australia), to coincide with an average flowering stem height of approximately $10 \mathrm{~cm}$ (generally middle to late August), and two additional applications of a tank mixture of difenoconazole at $125 \mathrm{~g}$ a.i./ha (as Score EC; Syngenta Australia), and chlorothalonil at 1,008 liters a.i./ha (as Bravo; Syngenta Australia) at 14- to 21-day intervals.

In first-year harvest fields, where disease intensity is often highest, the elucidation of a threshold beyond which defoliation and necrotic stem lesion severity will lead to loss of flowers (an important component of pyrethrin yield) will be useful to help growers make timely and cost- 
effective management decisions to achieve attainable yield potentials, such as reducing unnecessary fungicide applications. The objectives of this study were to quantify the effectiveness of the recommended fungicide protocol established in 2002 on disease intensity and yield, and to determine the minimum disease intensity thresholds beyond which yield is negatively impacted.

\section{MATERIALS AND METHODS}

Effect of the recommended fungicide protocol on disease intensity and yield. Field sites. Ninety-seven pyrethrum fields (46 in 2003 and 51 in 2004) ranging in age from the first to third harvest years were randomly selected from all pyrethrum production districts in Tasmania (Devonport/Central Coast/Wynyard). Fields were situated within a $150-\mathrm{km}$ range in northern Tasmania between the eastern boundary of UTM coordinate 55G 4628995435784 and western boundary coordinate 380146 5466162. All pyrethrum fields were no further than $30 \mathrm{~km}$ inland from the coast. Fifteen of the fields included in the study in 2003 were also monitored in 2004. Each field was grown using standard production practices which included irrigation, fertilizer, fungicide, and herbicide applications. Within each field, two plots $(10 \mathrm{~m}$ long $\times$ $24 \mathrm{~m}$ wide) were established. The first plot received the industry recommended fungicide protocol (21), which was applied by each grower using standard on-farm spray equipment. Fungicides were applied using a volume of 300 liters/ha at a pressure of approximately $200 \mathrm{kPa}$. The second plot did not receive any fungicide treatments. Plots were separated by a $5-\mathrm{m}$ border of pyrethrum that did not receive any fungicides.

Assessment of plant density and disease intensity. Plant density (the number of plants per square meter) was assessed between 14 and 18 July, just prior to the first application of fungicides. Plant density was determined by counting plants within five randomly placed $0.75 \mathrm{~m}^{2}$ quadrats in both fungicide-treated and nontreated plots. At that time, plants were still in a semidormant state, and the sampling unit (flowering stem) used for subsequent assessments had not yet developed. Disease intensity was assessed in all plots from July through November each year. Disease intensity was assessed by selecting 50 leaves from individual plants following a predetermined systematic sampling design along each of three linear transects covering the entire width of each plot (150 leaves in total). Disease severity on leaves (the proportion of leaf affected by necrosis) was determined by comparing diseased leaves to standard area diagrams depicting known levels of disease severity. These diagrams were constructed from scanned images of individual, full-size illustrations of pyrethrum leaves (20). The average severity of necrotic lesions on leaves from each plot was then estimated. All disease assessments were conducted by the same individual for both years. Moreover, this individual was trained and evaluated for the accuracy of their estimates using the disease assessment training program, "Severity.pro" $(13,14,16)$.

From August until November, the population of sampling units for disease intensity assessments was the flowering stems. In 2003, disease assessments were made from 23 to 27 August, 12 to 16 September, 7 to 12 October, and 13 to 18 November. In 2004, disease intensity was assessed from 25 to 30 August, 8 to 12 September, 6 to 11 October, and 11 to 17 November. For each assessment, 20 flowering stems were systematically selected from each of three linear transects covering the entire width of each plot (60 stems/plot in total). Flowering stems were cut at the base of each plant, stored at $4^{\circ} \mathrm{C}$, and assessed within $48 \mathrm{~h}$ of collection. Disease intensity assessments included: (i) defoliation severity (length of stem from the base at which leaves were either completely necrotic or abscised as a percentage of total stem length); (ii) incidence (\%) of stems with ray blight; and (iii) incidence (\%) of flowers with ray blight. The first two disease assessment methods also provided a measure of stem height and the number of flowers produced per stem, as described by Pethybridge et al. (17).

Assessment of flower maturity and pyrethrin yield. Flowers were hand-harvested from four systematically selected quadrats $\left(1 \mathrm{~m}^{2}\right)$ in both fungicide-treated and nontreated plots within each field. Harvesting of fields occurred between 12 and 17 December of each year (approximately 12 days prior to commercial harvest of the entire field). Flowers were bagged, stored at $4{ }^{\circ} \mathrm{C}$, and weighed within $24 \mathrm{~h}$ of collection. A subsample ( $20 \%$ of total sample) was dried at $60^{\circ} \mathrm{C}$ for $24 \mathrm{~h}$, and dry weight was recorded.

Subsamples were also randomly selected from the fresh flowers for extraction and quantification of pyrethrin content. These flowers were dried at $55^{\circ} \mathrm{C}$ for $48 \mathrm{~h}$ and stored at $-20^{\circ} \mathrm{C}$ for approximately 1 month prior to processing. Samples were ground to a fine powder, sonicated for 20 min with shaking, and allowed to stand for a further $16 \mathrm{~h}$ before being filtered through a $0.45-\mu \mathrm{m}$ membrane. Samples were analyzed using normal high-phase performance liquid chromatography on a Shimadzu system (11). The column was $8 \times 100$ $\mathrm{mm}$ Waters Resolve Silica $(5 \mu \mathrm{m})$ with a silica guard. The mobile phase was a solution of heptane and 4\% tetrahydrofuran injected at $4 \mathrm{ml} / \mathrm{min}$. Pyrethrin content was estimated by measuring ultraviolet light at a wavelength of $223 \mathrm{~nm}$ and interpreted by comparison to a validated reference standard of pyrethrins extracted from plant material.
Flower maturity was assessed on a further subsample $(200 \mathrm{~g})$ of fresh flowers collected from each of the fungicidetreated and nontreated plots. Flower maturity categories and calculation of the weighted mean average assessment of flower maturity have been previously described (21). In addition, flowers were sorted into diseased and healthy, and the incidence $(\%)$ of diseased flowers was determined.

Data analysis. The effect of the recommended fungicide protocol on plant physiological measures (plant density, stem height, and number of flowers per stem), as well as disease intensity assessments (defoliation severity, incidence of stems and flowers with ray blight) and yield components (dry weight of flowers [g], pyrethrin content [\%], flower maturity, and pyrethrin yield $[\mathrm{kg} / \mathrm{ha}])$, were analyzed by ANOVA (Genstat 5; version 3.2, Adept Scientific Inc., Bethesda, MD). Yield is expressed herein as the relative increase over the nontreated plots. Prior to all analyses, the incidence of stems and flowers with ray blight data was transformed using the equation: square-root $(x+1)$ to improve the normal distribution of the residuals.

Thresholds between disease measures. Field data. Tobit regression analyses were used to develop statistical threshold models among the different measures of disease intensity $(12,28)$. These analyses assumed that defoliation may have an impact on stem severity (proportion of stem area covered by necroses), which in turn may affect the incidence of flowers with ray blight. Disease intensity was assessed as described above, again using flowering stems as the sampling unit. Stems were selected along three 10-m line transects, approximately $20 \mathrm{~m}$ apart, in each of three pyrethrum fields: Sisters Creek (UTM 55G 380035 5465969), Penguin (418454 5447229), and Gawler (431264 5439973), 14 to 21 days prior to first harvest on 3 and 4 December 2002. Each transect was initiated within an area $(10 \mathrm{~m}$ long $\times 24 \mathrm{~m}$ wide) that had not been treated with fungicides. The remaining area of the pyrethrum fields received the recommended commercial fungicide protocol. Ten stems were systematically selected at $50-\mathrm{cm}$ intervals (20 points) along each transect (200 stems in total for each field). Flowering stems were clipped with secateurs from the base of the plants and transported to the laboratory at $4^{\circ} \mathrm{C}$ for measurements and disease assessment within $24 \mathrm{~h}$. For each flowering stem, defoliation severity and the incidence of flowers with ray blight were assessed, as well as stem severity. Severity assessments were conducted by the same person and disease area diagrams of stems were used as an assessment aid (13).

Data analysis. Tobit regression modeling is a left-censored regression model $(12,28)$ where the underlying error distri- 
bution, $\varepsilon_{i}^{*}$, is assumed to be normally distributed with mean 0 and variance $\sigma^{2}$ :

$$
Y_{i}^{*}=x_{i} \beta+\varepsilon_{i}^{*}
$$

Since none of the disease intensity measures can be less than 0 , the censoring event was defined as:

$$
\begin{aligned}
& Y_{i}=0 \text { if } Y_{i}^{*} \leq 0 \\
& Y_{i}=Y_{i}^{*} \text { if } Y_{i}^{*}>0
\end{aligned}
$$

Maximum likelihood estimation was used to fit parameter estimates of the regression model, which were then used to calculate the predicted value of the observed $Y_{i}^{\prime}$ 's as:

$$
E\left(Y_{i}\right)=\Phi\left(\frac{x_{i} \beta}{\sigma}\right)\left(x_{i} \beta+\sigma \lambda_{i}\right)
$$

where $x_{i} \beta$ represents the predicted response, $\sigma$ represents a scaling factor, and $\lambda_{i}$ is defined as:

$\lambda_{i}=\frac{\phi\left(x_{i} \beta / \sigma\right)}{\Phi\left(x_{i} \beta / \sigma\right)}$

where, $\phi$ represents the normal probability density and $\Phi$ represents the cumulative normal distribution functions, respectively $(12,28)$. We examined the following combination of models: (i) defoliation severity (X) and stem severity (Y), (ii) defoliation severity (X) and incidence of flowers with ray blight $(\mathrm{Y})$, and (iii) stem severity $(\mathrm{X})$ and incidence of flowers with ray blight (Y). Models were constructed for each individual replication within each locationyear using the survreg function in the survival library of $\mathrm{R}(\mathrm{R}$ 2.1.1, The $\mathrm{R}$ Project for Statistical Computing, online). Each model was compared with the null model (intercept-only) using a likelihood ratio test, with a $\chi^{2}$ test statistic. The determination of the subminimal threshold for the predictor variable was subsequently defined as the level of the stimulus X, below which there is no response in Y (29), or namely when the dependent value changed from flat to a linearly increasing value.

\section{RESULTS}

Effect of the recommended fungicide protocol on disease intensity and yield.

\begin{tabular}{|c|c|c|c|c|c|}
\hline Treatment & $\begin{array}{l}\text { Stem height } \\
\text { (cm) }\end{array}$ & $\begin{array}{l}\text { Defoliation } \\
\text { severity } \\
(\%)\end{array}$ & $\begin{array}{c}\text { Number of } \\
\text { flowers/stem }\end{array}$ & $\begin{array}{c}\text { Incidence of stems } \\
\text { with ray blight } \\
(\%)^{\mathrm{y}}\end{array}$ & $\begin{array}{c}\text { Incidence of flowers } \\
\text { with ray blight } \\
(\%)^{\mathrm{y}}\end{array}$ \\
\hline \multicolumn{6}{|l|}{ September } \\
\hline Fungicide protocol & $19.5 \mathrm{a}$ & $15 \mathrm{~b}$ & 0.8 & $1.26(0.59 \mathrm{~b})$ & $1.38(0.9 \mathrm{~b})$ \\
\hline Nontreated & $17.5 \mathrm{~b}$ & $40.8 \mathrm{a}$ & 0.6 & $3.5(11.3 \mathrm{a})$ & $3.93(14.4 \mathrm{a})$ \\
\hline LSD & 0.75 & 5.5 & $\ldots$ & 0.49 & 0.52 \\
\hline$P$ & $<0.001$ & $<0.001$ & $0.101(\mathrm{~ns})$ & $<0.001$ & $<0.001$ \\
\hline $\mathrm{CV}(\%)^{\mathrm{z}}$ & 14 & 46.4 & 84.8 & 37.1 & 36.9 \\
\hline \multicolumn{6}{|l|}{ October } \\
\hline Fungicide protocol & $38.3 \mathrm{a}$ & $10.7 \mathrm{~b}$ & $3.8 \mathrm{a}$ & $1.11(2.3 \mathrm{~b})$ & $1.07(0.14 \mathrm{~b})$ \\
\hline Nontreated & $29.3 \mathrm{~b}$ & $36.6 \mathrm{a}$ & $2.7 \mathrm{~b}$ & 3.54 (11.53 a) & 3.19 (9.18 a) \\
\hline LSD & 2.2 & 5.1 & 0.4 & 0.33 & 0.61 \\
\hline$P$ & $<0.001$ & $<0.001$ & $<0.001$ & $<0.001$ & $<0.001$ \\
\hline $\mathrm{CV}(\%)$ & 20.4 & 47.9 & 30.9 & 45.4 & 45.5 \\
\hline \multicolumn{6}{|l|}{ November } \\
\hline Fungicide protocol & $61.2 \mathrm{a}$ & $16.2 \mathrm{~b}$ & $6.3 \mathrm{a}$ & $1.09(0.19 \mathrm{~b})$ & $1.07(0.15 \mathrm{~b})$ \\
\hline Nontreated & $52.2 \mathrm{~b}$ & $35.5 \mathrm{a}$ & $4.3 \mathrm{~b}$ & $3.46(10.97 \mathrm{a})$ & $2.73(6.45 \mathrm{a})$ \\
\hline LSD & 2 & 4.5 & 0.4 & 0.49 & 0.48 \\
\hline$P$ & $<0.001$ & $<0.001$ & $<0.001$ & $<0.001$ & $<0.001$ \\
\hline $\mathrm{CV}(\%)$ & 13.8 & 38.3 & 21.5 & 34.6 & 41.5 \\
\hline
\end{tabular}
2003. During July (prior to fungicide ap-

Table 1. Impact of the commercial recommended fungicide protocol on stem height, defoliation severity, number of flowers per stem, and incidence of stems and flowers with ray blight for 46 pyrethrum fields in 2003 in northern Tasmania

${ }^{y}$ Data were transformed using a square root +1 transformation. Presented is the actual followed in parentheses by the backtransformed means.

\begin{tabular}{|c|c|c|c|c|c|}
\hline Treatment & $\begin{array}{l}\text { Stem height } \\
\text { (cm) }\end{array}$ & $\begin{array}{l}\text { Defoliation } \\
\text { severity } \\
(\%)\end{array}$ & $\begin{array}{c}\text { Number of } \\
\text { flowers/stem }\end{array}$ & $\begin{array}{c}\text { Incidence of stems } \\
\text { with ray blight } \\
(\%)^{\mathrm{y}}\end{array}$ & $\begin{array}{c}\text { Incidence of flowers } \\
\text { with ray blight } \\
(\%)^{\mathrm{y}}\end{array}$ \\
\hline \multicolumn{6}{|l|}{ September } \\
\hline Fungicide protocol & $14.5 \mathrm{a}$ & $12.8 \mathrm{~b}$ & 0.2 & $0.13(0.1 \mathrm{~b})$ & $0.11(0.09 \mathrm{~b})$ \\
\hline Nontreated & $12 \mathrm{~b}$ & $32.8 \mathrm{a}$ & 0.1 & $4.26(2.69 \mathrm{a})$ & $3.62(2.9 a)$ \\
\hline LSD & 0.9 & 3 & & 0.35 & 0.32 \\
\hline$P$ & $<0.001$ & $<0.001$ & 0.61 (ns) & $<0.001$ & $<0.001$ \\
\hline $\mathrm{CV}(\%)^{\mathrm{z}}$ & 15.1 & 52.2 & 95.5 & 44.2 & 42.3 \\
\hline \multicolumn{6}{|l|}{ October } \\
\hline Fungicide protocol & $37.6 \mathrm{a}$ & $18.9 \mathrm{~b}$ & $3.9 \mathrm{a}$ & $0.41(0.29 \mathrm{~b})$ & $0.15(0.12 \mathrm{~b})$ \\
\hline Nontreated & $29.1 \mathrm{~b}$ & $47.6 \mathrm{a}$ & $2.8 \mathrm{~b}$ & $19.12(15.81 \mathrm{a})$ & $14.33(11.46 \mathrm{a})$ \\
\hline LSD & 1.4 & 3.8 & 0.2 & 0.5 & 0.48 \\
\hline$P$ & $<0.001$ & $<0.001$ & $<0.001$ & $<0.001$ & $<0.001$ \\
\hline $\mathrm{CV}(\%)$ & 12.7 & 29.8 & 23.4 & 37.3 & 38.2 \\
\hline \multicolumn{6}{|l|}{ November } \\
\hline Fungicide protocol & $68.1 \mathrm{a}$ & $10.6 \mathrm{~b}$ & $6.5 \mathrm{a}$ & $1.1(0.79 \mathrm{~b})$ & $0.3(0.25 \mathrm{~b})$ \\
\hline Nontreated & $52.8 \mathrm{~b}$ & $46.8 \mathrm{a}$ & $3.9 \mathrm{~b}$ & $27.2(23.9 a)$ & $18.24(15.73 \mathrm{a})$ \\
\hline LSD & 2.5 & 4.6 & 0.4 & 0.51 & 0.45 \\
\hline$P$ & $<0.001$ & $<0.001$ & $<0.001$ & $<0.001$ & $<0.001$ \\
\hline $\mathrm{CV}(\%)$ & 9.1 & 32.6 & 13.3 & 32.1 & 31.7 \\
\hline
\end{tabular}

${ }^{\mathrm{z}} \mathrm{CV}(\%)=$ coefficient of variation.

Table 2. Impact of the commercial recommended fungicide protocol on stem height, defoliation severity, number of flowers per stem, and incidence of stems and flowers with ray blight for 51 pyrethrum fields in 2004 in northern Tasmania

${ }^{y}$ Data were transformed using a square root +1 transformation. Presented is the actual followed in parentheses by the backtransformed means.

${ }^{\mathrm{z}} \mathrm{CV}(\%)=$ coefficient of variation. 
plications), there was no significant difference in disease severity on leaves or plant density in fungicide-treated versus nontreated plots. Furthermore, no significant differences were detected in August for disease intensity $(P=0.231$ to 0.465$)$, stem height $(P=0.403)$, or the number of flowers per stem $(P=0.652)$ (data not shown). From September onward, the effect of the recommended fungicide protocol was significant $(P<0.001)$ for all assessment methods except for the number of flowers per stem. Pyrethrum plots treated using the recommended fungicide protocol resulted in a decrease in defoliation severity for September, October, and November assessments by 64, 71, and $55 \%$, respectively. The incidence of stems and flowers with ray blight was reduced by at least $93 \%$ in all cases. The maximum increase in stem height $(31 \%)$ from the recommended fungicide protocol occurred during October. The number of flowers per stem was increased by 41 and $47 \%$ in October and November, respectively, in plots treated using the recommended fungicide protocol (Table 1).

Plots treated using the recommended fungicide protocol also resulted in significant $(P<0.001)$ increases in the dry weight of flowers and pyrethrin yield. Relative to the nontreated pyrethrum plots, the dry weight of flowers and pyrethrin yield were increased by 76 and $81 \%$, respectively. Flower maturity and pyrethrin content/unit dry weight were similar between treatments (data not presented).

2004. Disease severity assessments on leaves and plant density in July were similar between treatments. Moreover, no significant differences were found for any measure of disease intensity $(P=0.254$ to $0.511)$, stem height $(P=0.226)$, and number of flowers per stem in August $(P=$ 0.151 ), prior to initiation of the recommended fungicide protocol (data not shown). After the recommended protocol was initiated, there were significant increases in stem height $(P<0.001)$ and significant decreases in defoliation severity from September onward $(P<0.001)$. Increases in stem height ranged from $21 \%$ in September to $29 \%$ in October and Novem-

Table 3. Tobit regression statistics for three sets of disease threshold comparisons: (i) stem severity (Y) versus defoliation severity (X); (ii) incidence of flowers with ray blight $(\mathrm{Y})$ versus defoliation severity $(\mathrm{X})$; and (iii) incidence of flowers with ray blight $(\mathrm{Y})$ versus stem severity $(\mathrm{X})$, from three pyrethrum fields in northern Tasmania

\begin{tabular}{|c|c|c|c|c|c|c|c|c|}
\hline $\begin{array}{l}\text { Location } \\
\text { Gradient }\end{array}$ & Dependent variable & Predictor variable & $\begin{array}{l}\text { Intercept } \\
( \pm \text { SE })\end{array}$ & $\begin{array}{l}\text { Predictor } \\
\quad( \pm \text { SE })\end{array}$ & $\begin{array}{l}\text { Log (scale) } \\
( \pm \text { SE) }\end{array}$ & $\begin{array}{c}\text { Log- } \\
\text { likelihood }\end{array}$ & $\chi^{2 z}$ & $P$ value \\
\hline \multicolumn{9}{|l|}{ Sullivan } \\
\hline 1 & Stem severity & Defoliation severity & $-53.5 \pm 14.87$ & $124.3 \pm 23.95$ & $2.0 \pm 0.31$ & -17.1 & 29.03 & $<0.0001$ \\
\hline 1 & $\begin{array}{l}\text { Incidence of flowers } \\
\text { with ray blight }\end{array}$ & Defoliation severity & $-0.36 \pm 0.114$ & $1.0 \pm 0.21$ & $-2.2 \pm 0.31$ & 1.3 & 20.31 & $<0.0001$ \\
\hline 1 & $\begin{array}{l}\text { Incidence of flowers } \\
\text { with ray blight }\end{array}$ & Stem severity & $-0.16 \pm 0.098$ & $0.01 \pm 0.004$ & $-1.6 \pm 0.33$ & -4.0 & 9.67 & 0.0019 \\
\hline 2 & Stem severity & Defoliation severity & $-31.7 \pm 7.86$ & $83.6 \pm 13.89$ & $2.0 \pm 0.28$ & -22.4 & 26.14 & $<0.0001$ \\
\hline 2 & $\begin{array}{l}\text { Incidence of flowers } \\
\text { with ray blight }\end{array}$ & Defoliation severity & $-0.41 \pm 0.071$ & $1.2 \pm 0.13$ & $-2.7 \pm 0.28$ & 6.0 & 33.16 & $<0.0001$ \\
\hline 2 & $\begin{array}{l}\text { Incidence of flowers } \\
\text { with ray blight }\end{array}$ & Stem severity & $-0.11 \pm 0.058$ & $0.02 \pm 0.003$ & $-2.2 \pm 0.31$ & 0.2 & 21.91 & $<0.0001$ \\
\hline 3 & Stem severity & Defoliation severity & $-22.7 \pm 3.31$ & $72.1 \pm 5.60$ & $1.2 \pm 0.28$ & -17.2 & 37.18 & $<0.0001$ \\
\hline 3 & $\begin{array}{l}\text { Incidence of flowers } \\
\text { with ray blight }\end{array}$ & Defoliation severity & $-0.34 \pm 0.103$ & $0.87 \pm 0.165$ & $-2.4 \pm 0.32$ & 2.7 & 22.91 & $<0.0001$ \\
\hline 3 & $\begin{array}{l}\text { Incidence of flowers } \\
\text { with ray blight }\end{array}$ & Stem severity & $-0.17 \pm 0.080$ & $0.01 \pm 0.003$ & $-2.2 \pm 0.33$ & 1.4 & 20.46 & $<0.0001$ \\
\hline \multicolumn{9}{|l|}{ McKenna } \\
\hline 1 & Stem severity & Defoliation severity & $-46.5 \pm 14.89$ & $102.0 \pm 21.36$ & $2.7 \pm 0.32$ & -22.6 & 20.86 & $<0.0001$ \\
\hline 1 & $\begin{array}{l}\text { Incidence of flowers } \\
\text { with ray blight }\end{array}$ & Defoliation severity & $-0.42 \pm 0.087$ & $1.2 \pm 0.13$ & $-2.5 \pm 0.31$ & 3.3 & 30.29 & $<0.0001$ \\
\hline 1 & $\begin{array}{l}\text { Incidence of flowers } \\
\text { with ray blight }\end{array}$ & Stem severity & $-0.24 \pm 0.122$ & $0.02 \pm 0.004$ & $-1.7 \pm 0.35$ & -2.3 & 18.94 & $<0.0001$ \\
\hline 2 & Stem severity & Defoliation severity & $-50.5 \pm 7.18$ & $141.8 \pm 9.72$ & $1.8 \pm 0.28$ & -20.5 & 42.56 & $<0.0001$ \\
\hline 2 & $\begin{array}{l}\text { Incidence of flowers } \\
\text { with ray blight }\end{array}$ & Defoliation severity & $-0.46 \pm 0.121$ & $1.14 \pm 0.179$ & $-1.9 \pm 0.27$ & 0.8 & 26.66 & $<0.0001$ \\
\hline 2 & $\begin{array}{l}\text { Incidence of flowers } \\
\text { with ray blight }\end{array}$ & Stem severity & $-0.14 \pm 0.070$ & $0.01 \pm 0.001$ & $-2.0 \pm 0.28$ & 0.4 & 25.89 & $<0.0001$ \\
\hline 3 & Stem severity & Defoliation severity & $-32.3 \pm 4.55$ & $113.4 \pm 8.12$ & $2.1 \pm 0.21$ & -40.9 & 44.28 & $<0.0001$ \\
\hline 3 & $\begin{array}{l}\text { Incidence of flowers } \\
\text { with ray blight }\end{array}$ & Defoliation severity & $-0.69 \pm 0.196$ & $1.73 \pm 0.297$ & $-1.5 \pm 0.28$ & -2.6 & 25.43 & $<0.0001$ \\
\hline 3 & $\begin{array}{l}\text { Incidence of flowers } \\
\text { with ray blight }\end{array}$ & Stem severity & $-0.29 \pm 0.145$ & $0.02 \pm 0.003$ & $-1.3 \pm 0.29$ & -4.4 & 21.86 & $<0.0001$ \\
\hline \multicolumn{9}{|l|}{ Nichols } \\
\hline 1 & Stem severity & Defoliation severity & $-34.6 \pm 3.67$ & $128.5 \pm 6.55$ & $2.0 \pm 0.19$ & -47.7 & 52.75 & $<0.0001$ \\
\hline 1 & $\begin{array}{l}\text { Incidence of flowers } \\
\text { with ray blight }\end{array}$ & Defoliation severity & $-0.51 \pm 0.204$ & $1.23 \pm 0.326$ & $-1.0 \pm 0.25$ & -8.4 & 12.86 & 0.0003 \\
\hline 1 & $\begin{array}{l}\text { Incidence of flowers } \\
\text { with ray blight }\end{array}$ & Stem severity & $-0.22 \pm 0.144$ & $0.01 \pm 0.003$ & $-1.0 \pm 0.25$ & -8.5 & 12.64 & 0.0004 \\
\hline 2 & Stem severity & Defoliation severity & $-49.4 \pm 10.41$ & $130.9 \pm 13.93$ & $2.8 \pm 0.21$ & -47.8 & 38.77 & $<0.0001$ \\
\hline 2 & $\begin{array}{l}\text { Incidence of flowers } \\
\text { with ray blight }\end{array}$ & Defoliation severity & $-0.53 \pm 0.144$ & $1.20 \pm 0.184$ & $-1.7 \pm 0.22$ & 1.1 & 32.16 & $<0.0001$ \\
\hline 2 & $\begin{array}{l}\text { Incidence of flowers } \\
\text { with ray blight }\end{array}$ & Stem severity & $-0.19 \pm 0.112$ & $0.01 \pm 0.002$ & $-1.3 \pm 0.23$ & -5.1 & 19.7 & $<0.0001$ \\
\hline 3 & Stem severity & Defoliation severity & $-31.1 \pm 10.00$ & $88.3 \pm 14.79$ & $3.1 \pm 0.20$ & -61.2 & 22.28 & $<0.0001$ \\
\hline 3 & $\begin{array}{l}\text { Incidence of flowers } \\
\text { with ray blight }\end{array}$ & Defoliation severity & $-0.45 \pm 0.119$ & $1.22 \pm 0.160$ & $-1.6 \pm 0.23$ & -1.9 & 29.46 & $<0.0001$ \\
\hline 3 & $\begin{array}{l}\text { Incidence of flowers } \\
\text { with ray blight }\end{array}$ & Stem severity & $-0.14 \pm 0.108$ & $0.01 \pm 0.002$ & $-1.2 \pm 0.24$ & -7.1 & 19.1 & $<0.0001$ \\
\hline
\end{tabular}

${ }^{\mathrm{z}} \chi^{2}$ test statistics based on a likelihood ratio test of the full (with predictor variable) and reduced (intercept-only) model. For all situations, the number of degrees of freedom was 1. 
ber, while defoliation severity was decreased in September, October, and November, by 61,60 , and $78 \%$, respectively. The number of flowers per stem was also significantly higher in plots receiving the recommended fungicide protocol in October $(41 \%)$ and November $(69 \%)$. The incidence of stems and flowers with ray blight was significantly lower in pyrethrum plots receiving the recommended fungicide protocol for all assessment times $(P<0.001)$ (Table 2).

Significant increases in the dry weight of flowers and pyrethrin yield were found in the plots receiving the recommended maturity $(P=0.681)$ and pyrethrin content/unit dry weight $(P=0.798)$ were similar between treatments. The recommended fungicide protocol increased the dry weight of flowers and pyrethrin yield by an average of 68 and $78 \%$, respectively.

Thresholds between disease measures. Across locations, all Tobit regression models were significant in terms of model fit, based on likelihood ratio tests against the intercept-only model (Table 3). Tobit regression statistics were used to estimate disease intensity thresholds, and results were similar across locations (Fig. 1). For defoliation severity $(\mathrm{X})$ and stem severity $(\mathrm{Y})$, the subminimal threshold beyond which stem severity began to increase linearly ranged between 26 and $45 \%$ ( 35.3 \pm 2.10 , mean $\pm \mathrm{SE}$ ). For defoliation severity $(\mathrm{X})$ and incidence of flowers with ray blight (Y), the subminimal threshold ranged from 33 to $44 \%(38.2 \pm 1.12)$, and fungicide protocol $(P<0.001)$. Flower

for stem severity $(\mathrm{X})$ and incidence of flowers with ray blight $(\mathrm{Y})$, the subminimal threshold ranged from 5 to $22 \%$ (13.7 $\pm 1.72)$.

\section{DISCUSSION}

This study has demonstrated that the recommended commercial fungicide protocol established in 2002 to manage ray blight disease caused by $P$. ligulicola is highly effective in reducing disease intensity and increasing pyrethrin yield. The three fungicides used in this program, azoxystrobin, difenoconazole, and chlorothalonil, are currently registered under minor use permit by the Australian Pesticides and Veterinary Medicines Authority. Recommended application rates were derived from field experimentation (21), with application frequency for members of various resistance groups designed to minimize the probability of directional selection for pathogen resistance. For example, fungicide applications are recommended to begin prior to disease onset in August, and fungicides with different active ingredients are utilized. Two of these fungicides, azoxystrobin and difenoconazole, are particularly at risk for the development of resistant strains over time $(4,25)$. Azoxystrobin is a member of the strobilurin group of fungicides that inhibit mitochondrial respiration by binding to the Qo or outer quinone-oxidizing pocket within the cytochrome $b_{1}$ complex (6). Difenoconazole and other demethylation inhibitor fungicides act by inhibiting the C-14 demethylation of 24-methylene-

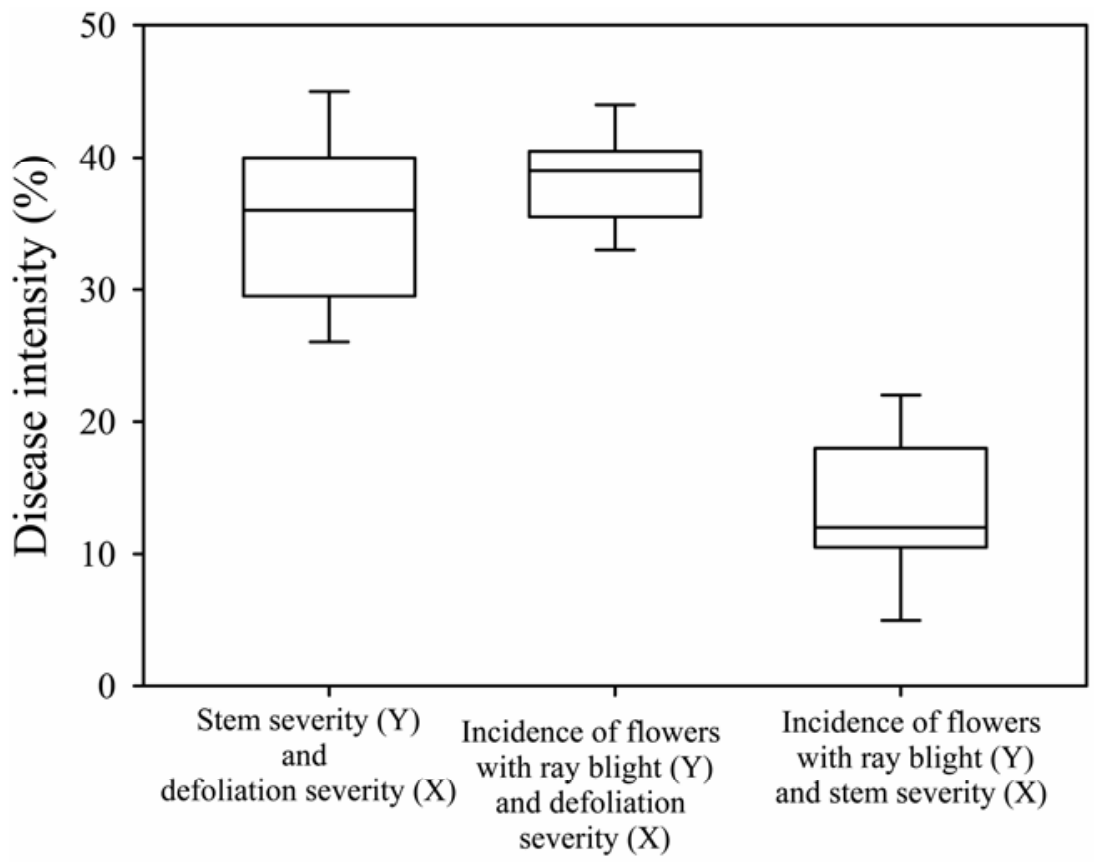

\section{Tobit regression group}

Fig. 1. Box plot indicating the median, interquartile, and entire range of thresholds calculated from using Tobit regression modeling for comparisons of (i) stem severity (Y) and defoliation severity (X), (ii) incidence of flowers with ray blight $(\mathrm{Y})$ and defoliation severity (X), and (iii) incidence of ray blight $(\mathrm{Y})$ versus stem severity $(\mathrm{X})$, from three pyrethrum fields in northern Tasmania. dihydrolanosterol, a precursor for sterol biosynthesis, used within fungal cell walls (8). Chlorothalonil is a broad-spectrum protectant fungicide with a low probability of directional selection for resistance within the target pathogen population.

In both years, disease intensity in nontreated versus fungicide-treated plots, and hence the difference in disease management between nontreated and the recommended protocol, was widest in October. One reason for this difference may be that the third fungicide application that is recommended (21) is not applied until late September, thereby resulting in maximum benefits to pyrethrum when it is most susceptible to ray blight disease (17). During this spring period in northern Tasmania, extended periods of rain favor rapid disease development and spore dispersal in pyrethrum (19) and chrysanthemum pathosystems $(1,2,9,10,26)$. After October, reductions in disease intensity may be due to rapid host growth, which outpaces disease development (17), or due to a decrease in the number of days with rain (19).

In both years of this study, the significant increases in overall pyrethrin yield $(\mathrm{kg} / \mathrm{ha})$ resulted from an increase in the dry weight of flowers and the number of flowers per stem. The dry weight of flowers is a function of the number of flowers produced per stem and the size of individual flowers. Previous studies in replicated trials have demonstrated that the application of fungicide results in taller and thicker stems that produce more secondary and tertiary branches, each of which will produce a flower on each stem terminus (21). In this study, we observed large increases in the production of flowers per stem, but not in pyrethrin content within the dried flowers, nor differences in flower maturity. Increases in pyrethrin content within the flowers have been demonstrated in other studies (21).

In addition to the yield calculations used to assess the impact of disease management tactics on pyrethrin yield (21), we have shown strong evidence documenting the benefits of the commercial fungicide program evaluated. In this study, the net return to the industry was also quantified by calculating the cost of ground-based fungicide applications using the recommended fungicide protocol. Quantifying yield losses (attainable yield minus actual grower yield) is paramount for the development of cost-effective management tactics that minimize the difference in yield between the two management extremes, i.e., when no management tactics are employed versus the use of all available disease management tactics. According to the operational definitions of Nutter and Guan (15), the benefits of the commercial fungicide program refer to actual yield, or the production currently being achieved above the yield production while utilizing the most current integrated disease manage- 
ment recommendations. However, sitespecific limitations to production may still exist from other biotic factors in this scenario. Using these calculations (data not shown), the net return averaged over the two seasons was AUD\$3,523/ha. Although the implementation of a commercial fungicide protocol for ray blight disease is clearly beneficial, variations in site (field) disease intensities have been observed over several seasons (19), indicating the existence of site risk factors as yet undefined. Reliable estimates of site-specific attainable yields facilitate nonbiased identification of spatial and temporal disease dynamics and factors that contribute to disease, yield loss risk, and the profitability of a cropping system $(7,15)$. Future research will examine the role of fieldspecific disease risk factors contributing to or inhibiting disease development to determine where and when intensive chemical disease management tactics are needed to enhance the recommended fungicide protocol. If sites of low disease risk can be identified, such sites may require less chemical inputs and hence reduced variable costs to the grower, with the added benefits of reducing the amount of pesticide introduced into the farm environment.

Finally, using Tobit regression, we were able to show that the different disease intensity assessment methods were strongly inter-related. For example in 2002, when defoliation severity reached approximately $35 \%$, we would expect the severity of necrotic lesions on stems to begin to increase linearly. Conversely, keeping defoliation severity below $35 \%$ ensured the severity of necrotic stem lesions would not increase. Thus, defoliation severity below $35 \%$ was subminimal for increases in stem severity to occur in 2002. Moreover, an increase of only $3 \%$ defoliation severity above $35 \%$ resulted in increasing numbers of diseased flowers and therefore the direct loss of an important component of pyrethrin yield (the number of healthy flowers per stem). If stem severity is used as the sampling threshold variable, then considerably lower disease intensity for this measure $(14 \%$ severity) would be the threshold beyond which one would expect to see a decrease in the number of diseased flowers. Using this approach, a fungicide management program that aims to keep defoliation severity below $35 \%$ in December may be critical for pyrethrum crops to achieve sitespecific attainable pyrethrin crop yields. To our knowledge, this is the first report of the use of Tobit regression to develop disease intensity-based thresholds to assist growers in making disease management decisions.

\section{ACKNOWLEDGMENTS}

This project was funded by the Australian Research Council Linkage programs, LP0211065 and LP0560562, and Botanical Resources Australia Pty. Ltd. We gratefully acknowledge Maurice Kerr for assistance with pyrethrin analyses, the excellent technical assistance of Craig Palmer (TIAR), and growers who participated in this study.

\section{LITERATURE CITED}

1. Baker, K. F., and Davis, L. H. 1959. Ascochyta disease of chrysanthemum appears in California. Calif. State Florists Assoc. Mag. 8:A-B.

2. Baker, K. F., Dimock, A. W., and Davis, L. H. 1949. Life history and control of the Ascochyta ray blight of chrysanthemum. Phytopathology 39:789-805.

3. Baker, K. F., Dimock, A. W., and Davis, L. H. 1961. Cause and prevention of the rapid spread of the Ascochyta disease of chrysanthemum. Phytopathology 51:96-101.

4. Bartlett, D. W., Clough, J. M., Godwin, J. R., Hall, A. A., Hamer, M., and Parr-Dobrzanski, B. 2002. The strobilurin fungicides. Pest Manage. Sci. 58:649-662.

5. Casida, J. E., and Quistad, G. B. 1995. Pyrethrum Flowers: Production, Chemistry, Toxicology and Uses. Oxford University Press, New York.

6. Gisi, U., Sierotzki, H., Cook, A., and McCaffery, A. 2002. Mechanisms influencing the evolution of resistance to Qo inhibitor fungicides. Pest Manage. Sci. 58:859-867.

7. Johnson, K. B. 1987. Defoliation, disease, and growth - a reply. Phytopathology 77:14951497.

8. Köller, W., and Scheinpflug, H. 1987. Fungal resistance to sterol biosynthesis inhibitors - a new challenge. Plant Dis. 71:1066-1074.

9. McCoy, R. E., and Dimock, A. W. 1973. Environmental factors regulating ascospore discharge by Mycosphaerella ligulicola. Phytopathology 63:586-589.

10. McCoy, R. E., Horst, R. K., and Dimock, A. W. 1972. Environmental factors regulating sexual and asexual reproduction by $M y$ cosphaerella ligulicola. Phytopathology 62:1188-1195.

11. McEldowney, A., and Menary, R. A. 1998. Analysis of pyrethrins in pyrethrin extracts by high-performance liquid chromatography. J. Chromatogr. 447:239-243.

12. Mittelhammer, R. C., Judge, G. G., and Miller, D. J. 2000. Econometric Foundations. Cambridge University Press, UK.

13. Nutter, F. W., Jr., and Esker, P. D. 2001. Dis- ease assessment keys. Pages 323-326 in: Encylopedia of Plant Pathology Vol. 1. O. C. Maloy and T. D. Murray, eds. John Wiley \& Sons, New York.

14. Nutter, F. W., Jr., Gleason, M. L., Jenco, J. H., and Christians, N. C. 1993. Assessing the accuracy, intra-rater repeatability, and inter-rater reliability of disease assessment systems. Phytopathology 83:806-812.

15. Nutter, F. W., Jr., and Guan, J. 2001. Disease losses. Pages 340-351 in: Encyclopaedia of Plant Pathology Vol. 1. O. C. Maloy and T. D. Murray, eds. John Wiley \& Sons, New York.

16. Nutter, F. W., Jr., and Schultz, P. M. 1995. Improving the accuracy and precision of disease assessments: Selection of methods and use of computer-aided training program. Can. J. Plant Pathol. 17:174-184.

17. Pethybridge, S. J., Esker, P. D., Hay, F. S., Wilson, C. R., and Nutter, F. W., Jr. 2005. Spatiotemporal description of epidemics caused by Phoma ligulicola in Tasmanian pyrethrum fields. Phytopathology 95:648-658.

18. Pethybridge, S. J., and Hay, F. S. 2001. Influence of Phoma ligulicola on yield and site factors on disease development in Tasmanian pyrethrum crops. Aust. Plant Pathol. 30:17-20.

19. Pethybridge, S. J., Hay, F. S., and Groom, T. 2003. Seasonal fluctuations associated with pyrethrum foliage in Tasmania. Aust. Plant Pathol. 32:223-230.

20. Pethybridge, S. J., Hay, F. S., and Wilson, C. R. 2004. Pathogenicity of fungi commonly isolated from foliar disease in Tasmanian pyrethrum crops. Aust. Plant Pathol. 33:441-444.

21. Pethybridge, S. J., Hay, F. S., Wilson, C. R., and Groom, T. 2005. Development of a fungicide-based management strategy for foliar disease caused by Phoma ligulicola in Tasmanian pyrethrum fields. Plant Dis. 89:1114-1120.

22. Pethybridge, S. J., and Wilson, C. R. 1998. Confirmation of ray blight disease of pyrethrum in Australia. Aust. Plant Pathol. 27:45-48.

23. Pethybridge, S. J., and Wilson, C. R. 2004. A survey for viruses and a viroid in Tasmanian pyrethrum crops. Aust. Plant Pathol. 33:301303.

24. Punithalingam, E. 1980. Didymella chrysanthemi, CMI Descriptions of Pathogenic Fungi and Bacteria. No. 662, Kew, UK.

25. Scheinpflug, H. 1988. History of DMI fungicides and monitoring for resistance. Pages 77 78 in: Fungicide resistance in North America American Phytopathological Society, St. Paul, $\mathrm{MN}$.

26. Stevens, F. L. 1907. The chrysanthemum ray blight. Bot. Gaz. 44:241-258.

27. Strider, D. L. 1994. Chrysanthemum diseases: A grower's guide. Rev. Chapingo Ser. Hortic. 1:131-135.

28. Tobin, J. 1958. Estimation of relationships for limited dependent variables. Econometrica 26:24-36.

29. Zadoks, J. C., and Schein, R. D. 1979. Epidemiology and Plant Disease Management. Oxford University Press, New York. 